\title{
Distribution of lead in lead-containing aluminium alloys obtained by liquid phase co-spray forming technique
}

\author{
YU FUXIAO, E S DWARAKADASA* and S RANGANATHAN \\ Department of Metallurgy, Indian Institute of Science, Bangalore 560012 , India \\ MS received 31 August 1998; revised 30 August 1999
}

\begin{abstract}
Liquid phase co-spray forming (LPCSF) technique was employed to produce $\mathrm{Al}-\mathrm{Pb}$ and $\mathrm{Al}-\mathrm{Si}-\mathrm{Pb}$ alloys to show that it is possible, using this technique, to distribute lead into very fine-sized particles in $\mathrm{Al} / \mathrm{Al}$ alloy matrix at low melt temperatures. Microstructural studies were carried out to explore the mechanisms governing lead distribution in the matrix of the alloys during processing. Results showed that, regardless of the alloy compositions and experimental conditions, the microstructures of the preforms exhibited great similarity, i.e. less uniform distribution of $\mathrm{Pb}$ particles in the base region, and uniform distribution of fine $\mathrm{Pb}$ particles in the equiaxed region. During LPCSF process, the behaviour of $\mathrm{Pb}$ droplets was similar to that of ceramic particles, except that the shape and size of liquid $\mathrm{Pb}$ phase varied corresponding to local solidification condition.
\end{abstract}

Keywords. Liquid phase co-spray forming; microstructure; aluminium lead alloys.

\section{Introduction}

The industrial application of lead-containing aluminium alloys is greatly limited by the difficulty in its manufacture. The one basic problem in the manufacturing of $\mathrm{Pb}$-containing $\mathrm{Al}$ alloys is of insolubility of lead in aluminium, which makes it imperative to heat the liquid mixture to a high temperature, thereby requiring a very high energy input. For example, to generate a homogeneous liquid solution of $\mathrm{Al}-\mathrm{Pb}$ alloy with $15 \% \mathrm{~Pb}$ (weight percent), a temperature of about $1500 \mathrm{~K}$ is needed. The second problem arises from the wide density difference between $\mathrm{Al}$ and $\mathrm{Pb}$, which greatly increases the kinetics of $\mathrm{Pb}$ segregation before and after the onset of solidification. Thus techniques different from conventional casting must be employed to prevent lead segregation in the alloys. So far, several advanced solidification techniques (Gorbunov et al 1973; Pathak et al 1979; Zhang et al 1988; Ojha et al 1992; Ohashi 1992; Berrenberg and Mergen 1993), as well as powder metallurgy processing (Mackay 1977; Kasuhiro et al 1993) have been employed to generate the lead-containing aluminium alloys having a uniform distribution of lead phase. However, these techniques face problems of higher energy consumption and the generation of coarse microstructures. It is worth noting that among these techniques, spray forming has exhibited its advantages in generating a fine $\mathrm{Pb}$ particle distribution in $\mathrm{Al}$ matrix without the formation of dendritic microstructure in the Al matrix phase (Zhang et al 1988; Ojha et al 1992).

\footnotetext{
*Author for correspondence
}

Spray forming is a process that employs gas atomization of a liquid metal stream, and subsequent deposition of the sprayed particles on to a substrate to form a condensed preform. The ability of this technique to generate materials with refined equiaxed microstructure and near absence of segregation are the reasons for the observed striking feature of spray formed products (Grant 1995). Following the pioneering work of Singer (1970) in the early seventies, spray forming has been developed not only to produce nearly all types of ferrous and nonferrous alloys but also metal matrix composites. The processes developed so far include atomization and co-deposition (Fishman 1986; Gupta et al 1990), reactive atomization and deposition (Zeng et al 1992), centrifugal spray forming (Rickinson 1981) and uniform-droplet spray forming (Passow et al 1993).

This work reports a modification of the spray-forming process, viz. liquid phase co-spray forming (LPCSF), that has been developed to generate $\mathrm{Al}-\mathrm{Pb}$ and $\mathrm{Al}-\mathrm{Si}-\mathrm{Pb}$ alloys. The schematic diagram of this process is given in figure 1. This technique differs from other spray-forming techniques in the use of two crucibles that separate the liquid phases before their atomization. The temperatures of the two liquid metals could be maintained individually at different levels before atomization depending on the specific system and other considerations. Upon pouring, the two liquid phases flow down through the metal delivery tubes and meet at the tip of the atomizer exit. Atomization, in this technique, functions not only to disintegrate the stream of liquid metals into fine droplets and subsequently cool these droplets and deliver them on to the substrate but also to mix the two phases in the form 
of fine droplets within the spray cone. The composition of the preform to be produced therefore depends on the deposit-rate ratio of the two liquid phases, which in turn depends on the ratio of the flow rates of the two liquids at the atomizer exit. Atomization and co-deposition process, which is generally employed to produce metal matrix composites (MMCs) (Fishman 1986; Gupta et al 1990), differs from LPCSF process in that in the former case coatomization of liquid phases is absent. Therefore, the name liquid phase co-spray forming was given to the present technique to emphasize this difference.

\section{Materials and experimental procedure}

To investigate the general characteristics and the mechanism of $\mathrm{Pb}$ particle distribution in the matrix alloys, different alloy systems and experimental conditions were selected to generate an $\mathrm{Al}-10 \mathrm{~Pb}$ and an $\mathrm{Al}-11.5 \mathrm{Si}-15 \mathrm{~Pb}$ alloy, respectively. While commercial grade $\mathrm{Al}(99.5 \%)$ and alloy LM6 (Si $11.47 \%, \mathrm{Fe} 0.37 \%, \mathrm{Cu} 0.19 \%, \mathrm{Mg}$ $0.18 \%$, Mn $0.14 \%$, Al balance) were used in the two experiments as the matrix alloy, commercial grade lead was used in both experiments for $\mathrm{Pb}$ addition. The atomizer used was an annular confined type convergentdivergent nozzle. An $\mathrm{Al}_{2} \mathrm{O}_{3}$-coated graphite crucible, with a hole at the bottom, acted as the outer crucible (figure 1).

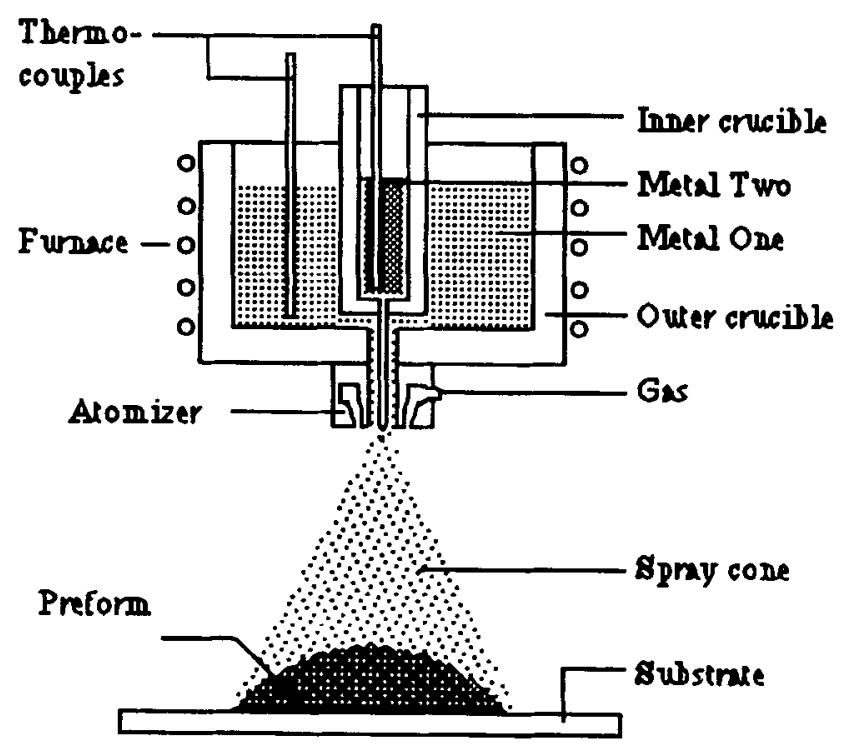

Figure 1. Schematic illustration of liquid phase co-spray forming setup.
The inner crucible was of stainless steel tube, which too was coated with $\mathrm{Al}_{2} \mathrm{O}_{3}$ on its inner and outer surfaces. This inner crucible acted both as the stopper for the outer crucible during melting, and as the flow-rate controller of the melt in the outer crucible during pouring. A tapered stainless steel rod was used as the stopper for the inner crucible, and the flow-rate controller of the melt in it. A fixed amount of $\mathrm{Al}$ and $\mathrm{Pb}$ or $\mathrm{LM} 6$ and $\mathrm{Pb}$ was charged in the outer and inner crucibles, respectively in the two experiments before heating in the resistance furnace. During melting, temperature of the alloys in the crucibles was continuously monitored by a chromel-alumel thermocouple. A gas regulator controlled the flow rate of the inert gas for atomization. Before pouring, a gas flow was initiated to create an environment of low-oxygen content, in order to reduce oxidation level during spray. Following atomization, the droplets were allowed to deposit on to the substrate positioned at a fixed distance below the atomizer.

The detailed experimental conditions of the two experiments are given in table 1 . A bell-shaped $\mathrm{Al}-\mathrm{Pb}$ alloy preform with a height of $\sim 30 \mathrm{~mm}$ and a diameter of $\sim 150 \mathrm{~mm}$ at the base, and a bell-shaped Al-Si-Pb alloy preform with a height of about $70 \mathrm{~mm}$ and base diameter of $\sim 150 \mathrm{~mm}$ were obtained in the two experiments as shown (figure 2). Samples cut out from the different regions of the preforms were prepared by standard metallographic techniques, followed by electropolishing. These were examined by scanning electron microscopy (SEM) (Model JSM 840A) in secondary electron (SE) or back scatted electron (BE) mode. Chemical analysis of $\mathrm{Pb}$ content was also carried out for samples cut out from the preforms.

\section{Results and discussion}

The chemical analysis of $\mathrm{Pb}$ concentration in the $\mathrm{Al}-\mathrm{Pb}$ alloy preform showed $\mathrm{Pb}$ concentration varying from 12.7 to $9.4 \%$ from the base to the top along the centre of the preform. The region with higher $\mathrm{Pb}$ concentration $(12.7 \%)$ was about $5 \mathrm{~mm}$ thick. But, if this part of preform was not taken into account, the average $\mathrm{Pb}$ concentration in the preform was $\sim 10.4 \%$. In the $\mathrm{Al}-\mathrm{Si}$ $\mathrm{Pb}$ alloy preform, the $\mathrm{Pb}$ concentration was relatively uniform, i.e. $14 \cdot 8 \pm 0.5 \%$. The variation of $\mathrm{Pb}$ concentration is believed to be a result of the variation of the flow rate ratio of $\mathrm{Al}$ alloy and $\mathrm{Pb}$ during atomization, which in turn is a result of the experimental setup and operational skill needed for running the experiment.

Table 1. Experimental conditions in LPCSF.

\begin{tabular}{lcccccc}
\hline & Gas & $\begin{array}{c}\text { Pressure } \\
(\mathrm{MPa})\end{array}$ & $\begin{array}{c}\text { Metal flow rate } \\
(\mathrm{g} / \mathrm{s})\end{array}$ & Substrate & $\begin{array}{c}\text { Distance } \\
(\mathrm{mm})\end{array}$ & $\begin{array}{c}\text { Pouring temp. } \\
(\mathrm{K})\end{array}$ \\
\hline $\mathrm{Al}-\mathrm{Pb}$ & $\mathrm{Ar}$ & 1.2 & 75 & Steel & 370 & 1073 \\
$\mathrm{Al}-\mathrm{Si}-\mathrm{Pb}$ & $\mathrm{N}$ & 1.6 & 75 & Copper & 500 & 1003 \\
\hline
\end{tabular}


Even though the size, composition of the preforms, and the experimental conditions in the two experiments were different, the microstructures of the two preforms exhibited a great similarity. In the regions of the preforms adjacent to the substrate, the microstructure consists of pre-solidified matrix alloy powder, porosity and a fine matrix alloy structure, while $\mathrm{Pb}$ phase particles are less uniformly distributed (figures $2 \mathrm{~b}, 3 \mathrm{~b}$, and $3 \mathrm{~d}$ ). The rapidly solidified microstructures of pre-solidified Al-Si droplets and the $\mathrm{Pb}$ particles among these powders can be seen from figure $3 \mathrm{~d}$. The thickness of this region is $\sim 4-5 \mathrm{~mm}$
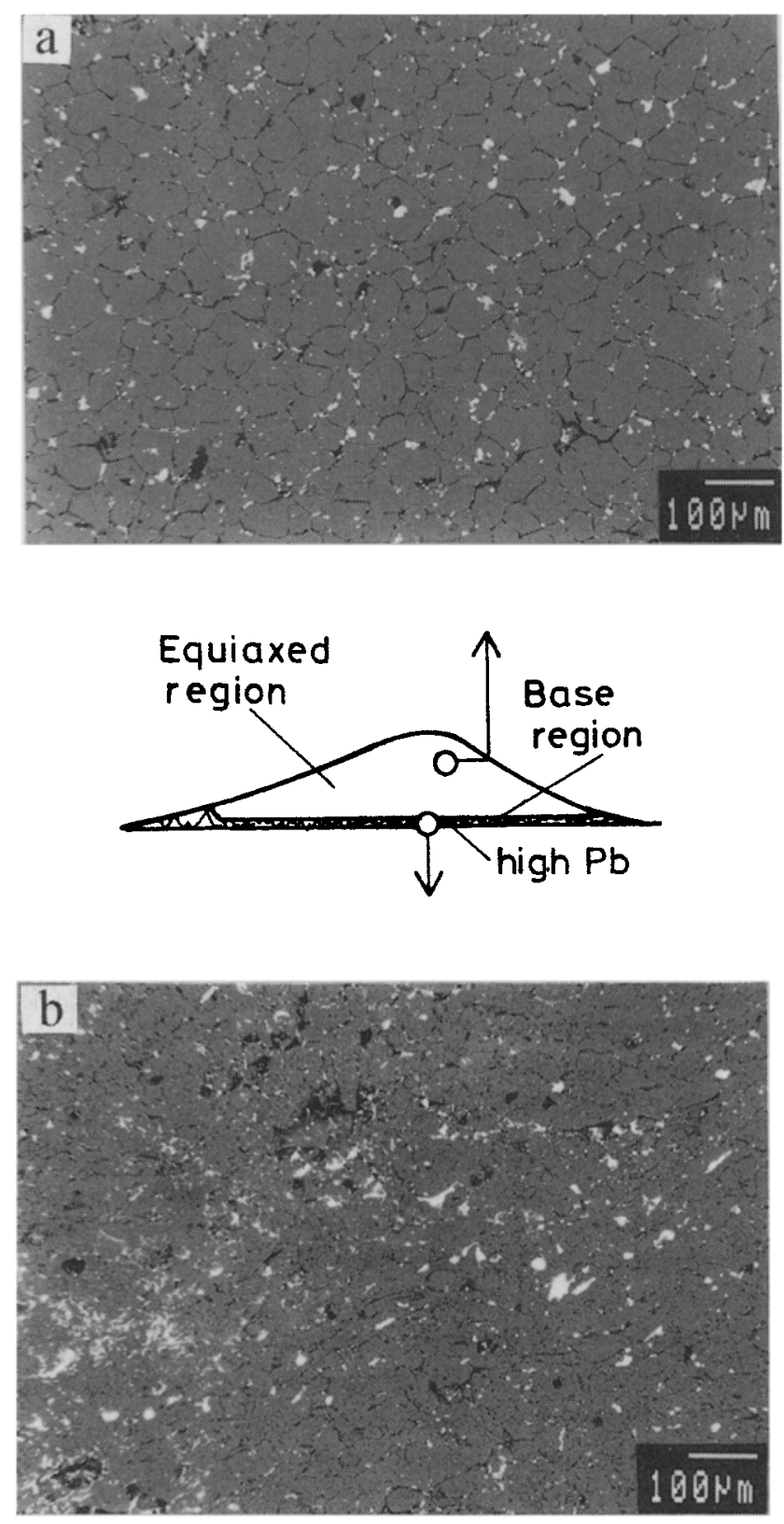

Figure 2. $\mathrm{BE}$ micrographs showing $\mathrm{Pb}$ distribution in $\mathrm{Al}-\mathrm{Pb}$ preform: (a) in the equiaxed region, (b) in the base region. Notice the bright colour of $\mathrm{Pb}$ phase in the $\mathrm{BE}$ images due to its high atomic number. at the centre of the preform. Away from the base region, the microstructure is characterized by an equiaxed grain structure of matrix alloys with uniformly distributed lead particles either at the grain boundaries or in the grain interiors. This region is named equiaxed region. The equiaxed aluminium grains with uniform lead particle distribution in $\mathrm{Al}-\mathrm{Pb}$ preform are shown in figure 2a. In the equiaxed region of $\mathrm{Al}-\mathrm{Si}-\mathrm{Pb}$ preform in the mechanically polished condition, irregular-shaped $\mathrm{Pb}$ particles with 'tails' can be seen (figure 3a). After electropolishing, these 'tails' of $\mathrm{Pb}$ particles vanished as these were dissolved by chemical action (figure $3 \mathrm{c}$ ). The facetedequiaxed $\mathrm{Si}$ particles can thus be seen largely located in the Al grain boundaries.

The separation of the liquid $\mathrm{A} 1 / \mathrm{Al}$ alloy and $\mathrm{Pb}$ before atomization avoided the need for exceeding immiscibility gap between $\mathrm{Al}$ and $\mathrm{Pb}$ in the liquid state, and thus obviated the requirement for high temperature to obtain a single-phase liquid $\mathrm{Al}-\mathrm{Pb}$ solution. The fine microstructures and uniform distribution of $\mathrm{Pb}$ in the equiaxed regions of the preforms, as well as the low-pouring temperature show distinctly the advantages of LPCSF technique. The microstructural similarity between the two preforms indicates that the mechanisms governing the microstructure formation and lead distribution are the same.

The $\mathrm{Pb}$ phase during LPCSF process behaves similar to ceramic particles during the atomization and codeposition process in generating MMCs, except that the shape and the state (liquid/solid) of $\mathrm{Pb}$ can change during the LPCSF. It can therefore be reasonably assumed that on the deposit surface, during deposition, the $\mathrm{Pb}$ phase was in a liquid state due to its low melting point. On the basis of comparing the $\mathrm{Pb}$ distribution in the base regions of the preforms with those found in the regions with an equiaxed structure (figures $2 a, 2 b, 3 a$ and $3 b$ ), and recalling that the structure in the lower-most portion of the preform was always formed from a droplet population with a lower liquid fraction (Grant 1995); it could be concluded that the liquid of the matrix alloy on the top surface of the deposit contributed to liquid $\mathrm{Pb}$ rearrangement during the deposition of lead. Also, the uniform distribution of $\mathrm{Pb}$ in the equiaxed regions indicates that a vigorous convection existed on the top surface of the deposits during deposition.

Thus, on the basis of the proposed mechanisms regarding the formation of equiaxed microstructure in the spray-formed products (Yu et al 1996; Yu 1998) and in the light of the mechanisms proposed by Gupta et al (1990) regarding the ceramic particle distribution in the matrix alloy during co-deposition, the microstructure formation in the $\mathrm{Pb}$ containing $\mathrm{Al}$ alloys during LPCSF can be described to be a result of the following events: The impact of fully solidified powders, semisolid droplets and full liquid droplets on the top surface of the deposit led to formation of solid powder particles and dendritic blocks immersed in the liquid films consisting of $\mathrm{Pb}$ and 
matrix alloy, resulting from the strong convection. With solidification in progress, the thickness of the liquid film reduced and the liquid $\mathrm{Pb}$ was constricted into regions, which later became grain boundaries and grain junctions.

Unlike the ceramic particles which might be pushed out of the liquid films, the liquid $\mathrm{Pb}$ most likely experiences a balance between the gravity force due to its large density and a combination of the repulsive forces from the solidification fronts, and capillary forces and fluid convective forces. As a result, large $\mathrm{Pb}$ particles usually get located in the grain junctions with their tails along the grain boundaries. Some individual liquid $\mathrm{Pb}$ particles might have no time to join the larger ones before the solidification fronts of two matrix grains meet, and hence would be constrained leading to individual $\mathrm{Pb}$ particles at the grain boundaries. The coarsening of the presolidified powders and dendritic blocks results in equiaxed $\mathrm{Al}$ grains in $\mathrm{Al}-\mathrm{Pb}$ alloy, and equiaxed $\mathrm{Al}$ grain with most of equiaxed silicon particles located at the $\mathrm{Al}$ grain boundaries in $\mathrm{Al}-\mathrm{Si}-\mathrm{Pb}$ alloy. Once the solid $\mathrm{Al}$ dendrites or cells trapped the liquid $\mathrm{Pb}$, the $\mathrm{Pb}$ droplets cannot therefore diffuse out of the trap owing to the near-zero solubility in solid Al. Thus some of the $\mathrm{Pb}$ particles might be trapped in the $\mathrm{Al}$ grain interiors (figures $2 \mathrm{a}$ and $3 \mathrm{a}$ ). On the other hand at the base regions of the preforms, since the overall liquid fraction of $\mathrm{Al}$ or $\mathrm{Al}-\mathrm{Si}$ droplets is less, liquid $\mathrm{Pb}$ has less freedom to move. Hence a non-uniform distribution of $\mathrm{Pb}$ in the matrix is expected. The observed porosity is a direct consequence of the presence of insufficient liquid to till the space among the presolidified droplets.
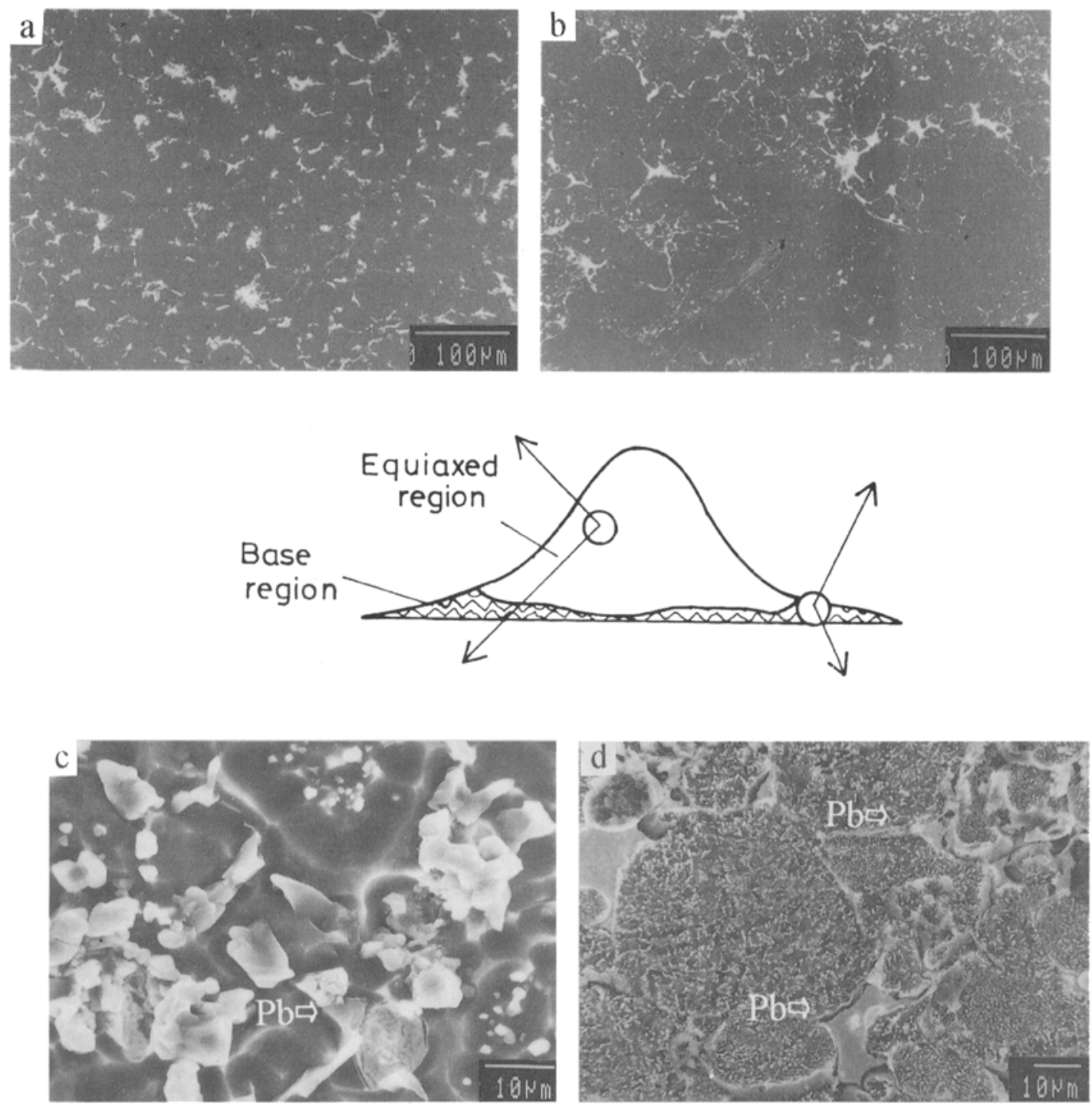

Figure 3. $\mathrm{BE}$ micrographs showing $\mathrm{Pb}$ distribution (a) in the equiaxed region and (b) in the base region of $\mathrm{Al}-11.5 \mathrm{Si}-15 \mathrm{~Pb}$ preform. SE micrographs showing morphologies of $\mathrm{Si}$ particles as well as $\mathrm{Pb}$ particles (c) in the equiaxed region and (d) in the base region. 


\section{Conclusions}

Two lead-containing aluminium alloys $(\mathrm{Al}-10 \mathrm{~Pb}$ and $\mathrm{Al}-11.5 \mathrm{Si}-15 \mathrm{~Pb}$ ) were generated by liquid phase co-spray forming (LPCSF) under different experimental conditions. The immiscibility of $\mathrm{Al}$ and $\mathrm{Pb}$ in the liquid state was avoided so that the process could take place at the low pouring temperature. Regardless of the alloy compositions and experimental conditions, the microstructures of the preforms exhibited great similarity, i.e. there was less uniform distribution of $\mathrm{Pb}$ particles in the base region, while fine $\mathrm{Pb}$ particles distributed uniformly in equiaxed region. During LPCSF process, the behaviour of $\mathrm{Pb}$ droplets was similar to that of ceramic particles except that the shape and size of liquid- $\mathrm{Pb}$ phase varied corresponding to local solidification condition.

\section{Acknowledgement}

Yu Fuxiao's study in the Department of Metallurgy, Indian Institute of Science, Bangalore, from 1993 to 1997 was financially supported by the Indo-China Cultural Exchange Programme under the aegis of ICCR.

\section{References}

Berrenberg Th and Mergen R 1993 Mater. Sci. Eng. A173 413 Fishman S G 1986 J. Metals 3826
Gorbunov V G, Parshin V D and Panin V V 1973 Russ. Cast. Prod. 9353

Grant P S 1995 Prog. Mater. Sci. 39497

Gupta M, Mohamed F A and Lavernia E J 1990 Mater. Manuf. Proc. 5165

Kasuhiro Nishiyama, Yasunori Kotani, Kiyoshi Miyama and Soukichi Umekawa 1993 Jpn. Soc. Powder Metall. 40 645

MacKay Michael L 1977 Met. Prog. 632

Ohashi J 1992 Jpn. Inst. Light Metal 42568

Ojha S N, Pandey O P, Tripathi Bhauk, Kumar M and Ramachandra C 1992 Mater. Trans. JIM 33519

Passow C H, Chun J-H and Ando T 1993 Metall. Trans. A24 1187

Pathak J P, Tiwari S N and Malhotra S L 1979 Metals Tech. 6 442

Rickinson B A 1981 Powder Metall. 11

Singer A R E 1970 Met. Mater. 426

Yu Fuxiao 1998 Development of liquid phase co-spray forming and its application to $\mathrm{Al}-\mathrm{Si}-\mathrm{Pb}$ alloys, Ph.D thesis, Indian Institute of Science, Bangalore

Yu Fuxiao, Dwarakadasa E S and Ranganathan S 1996 Proc. 3rd int. conf. on spray forming, Total technology for advanced materials (UK: TMS) p. 313

Zeng Xiaolu, Liu Huimin, Chu Men G and Lavernia Enrique J 1992 Metall. Trans. A23 3394

Zhang Younchang, Hao Yunyan, Liu Zhanfa and Chen Guiyun 1988 Mater. Sci. Eng. 98119 